\title{
Preparation of a coal cinder-zeolite ball and its adsorption performance for ammonia nitrogen
}

\author{
Huibo $\mathrm{Yu}^{1}$, Weijun Tian ${ }^{1,2^{*}}$, Ruying Huang ${ }^{1}$, Yongmei Wang ${ }^{1}$ \\ 1. College of Environmental Science and Engineering, Ocean University of China, Qingdao, \\ Shandong, China; \\ 2. Key Laboratory of Marine Environmental Science and Ecology, Ministry of Education, Qingdao, \\ Shandong, China
}

Keywords: coal cinder-zeolite ball, ammonia nitrogen; adsorption; kinetic

\begin{abstract}
Coal cinder and zeolite have been widely studied in wastewater treatment. However there are some problems with the materials, such as low mechanical strength, poor water resistance, difficult recovery of coal cinder, and poor stability, easy powder, high price of zeolite. To resolve these problems, a coal cinder-zeolite ball was developed with modified PVA adhesive. Then the adsorption performance and thermal regeneration for ammonia nitrogen were studied. The results showed that the adsorption process of the sorbent had a good match with pseudo-second-order kinetic model and Langmuir equation; the adsorption capacity of ammonia nitrogen calculated from Langmuir equation was $0.18 \mathrm{mg} / \mathrm{g}$, which was larger than that obtained from coal cinder alone. And the sorbent has a good regeneration performance. and the best parameters of regeneration in the process of experiments was $170^{\circ} \mathrm{C}$, $4 \mathrm{~h}$. Under this condition, the regeneration efficiency reached $74 \%$.
\end{abstract}

\section{Introduction}

Ammonia nitrogen is one of the predominant pollutions in water and can lead to water eutrophication, which is also an important pollution emission index in Liaohe estuary wetland. Liaohe estuary wetland is the last barrier of the pollutants

flow into the sea, the high concentration of ammonia nitrogen in wetland water not only threaten coastal wetland ecological environment, but also cause the increase of pollutants flux and accelerate the eutrophication of coastal water[Kuang Deshun,2010]. Therefore, it is necessary to research on the methods of removing ammonia nitrogen effectively, which is of great significance to the protection of coastal wetland and coastal environment.

Coal cinder is widespread solid waste from indusrial manufacture and daily life in China, and the main chemical composition is $\mathrm{SiO}_{2}, \mathrm{Al}_{2} \mathrm{O}_{3}, \mathrm{Fe}_{2} \mathrm{O}_{3}, \mathrm{CaO}$, Sulfur, magnesium and carbon etc[Wang S,2006].Because of its porous structure, large surface area and low price,coal cinder has been widely used in wastewater treatment process, so as to realize the resource utilization of solid waste, which can play a role in the removal of heavy metals, ammonia nitrogen[Alinnor,2007][ChenLirong,2013]. However, there are some disadvantages in the use of cinder, such as low mechanical strength, not resistant to water, uneasy to recovery, and its direct use may lead to aluminum, lead, chromium and other heavy metals dissolution, which may bring secondary pollution to water bodies. Zeolite is another adsorption material, with frame shape structure, rich pores, and large surface area (400 800 $\mathrm{m}^{2} / \mathrm{g}$ ) [Gao Junmin,2001], which adsorb ammonia nitrogen. Besides the regeneration performance is good. Studies have shown that [Tang Dengyong, 2011] [Sprynskyy,2005]natural zeolite has a good removal effect of ammonia nitrogen, but its price is high, which limits its wide application in a certain extent.

Therefore, this study prepared coal cinder-zeolite honeycombed sorbent, using modified PVA adhesive, hydrochloric acid modified coal cinder and zeolite as raw materials. To investigate the adsorption performance of ammonia nitrogen, adsorption kinetics and adsorption isotherm experiments were carried out; and using adsorption experiments to evaluate the regeneration performance, so as to get a kind of new water treatment material with low price, high 
mechanical strength, and resistance to shock loading.

\section{Materials and Methods}

\section{Experimental materials.}

Boiler combustion coal cinder; Natural zeolite(Guangzhou, China); Polyvinyl alcohol(1799); succinic acid(AR);Hydrochloric acid(AR); Ammonium chloride(AR).

Grinder(DF-4,ZhejiangZhongke Building Material Cquipment Co.

Ltd.); Scanning electronmicroscope (JSM-840,JEOL); Horizontal oscillator (LRH-250-G250L, Shaoguan Taihong medical machinery Co. Ltd.); Drying box(DHG-9140, Shanghai Jinghong

Experimental Equipment Co. Ltd.); UV VIS spectrophotometer(The 18 series, Beijing Purkinje General Instrument Co. Ltd.).

\section{Experimental methods.}

1) Preparation of modified PVA adhesive

The PVA (1799) was dissolved under the condition of $90{ }^{\circ} \mathrm{C}$ water bath, then succinic acid was added when water bath temperature was $85{ }^{\circ} \mathrm{C}$. The solution was stirred well and cooling to room temperature[Chen Lin,2012]. The rate of PVA (w:v) was 7\%.

2)The preparation of coal cinder-zeolite ball

The cinder(20 mesh) was modified using $\mathrm{HCl}(6 \mathrm{~mol} / \mathrm{L})$ soaking for $24 \mathrm{~h}$, and washed close to neutral, and then dried. Then the coal cinder and zeolite(20 mesh) was mixed with the ratio of 2:1, then suitable amount of modified PVA adhesive was added into that mixture. The coal-zeolite ball about $3 \mathrm{~cm}$ in diameter was made in ball machine, and then the ball was dried under the condition of $70{ }^{\circ} \mathrm{C}$, soaked in water for $2 \sim 3$ weeks, taken out and dried again and then can be used.

3) Adsorption kinetic experiment

The $600 \mathrm{ml}$ water was prepared with ammonium chloride $(10 \mathrm{mg} / \mathrm{L})$. The three coal cinder-zeolite balls were placed in the water, and then were shocked constantly at $25^{\circ} \mathrm{C}$. The samples were collected at fixed time. According to concentration of ammonia nitrogen in the simulation water, the adsorption of ammonia nitrogen was calculated.

$$
q_{e}\left(q_{t}\right)=\frac{\left(c_{0}-c_{t}\right) v}{m}
$$

$\mathrm{q}_{\mathrm{e}}$ is the equilibrium adsorption quantity, $\mathrm{mg} / \mathrm{g} ; \mathrm{q}_{\mathrm{t}}$ is the adsorption quantity of adsorption when time is $\mathrm{t}, \mathrm{mg} / \mathrm{g} ; c_{0}$ is initial concentration of ammonia nitrogen in water samples, $\mathrm{mg} / \mathrm{L} ; c_{\mathrm{t}}$ is concentration of ammonia nitrogen in water samples at adsorption time $\mathrm{t}, \mathrm{mg} / \mathrm{L} ; \mathrm{v}$ is the volume of solution, $\mathrm{mL} ; m$ is the quality of coal-zeolite ball, $\mathrm{g}$.

4) Isothermal adsorption experiment

The $200 \mathrm{ml}$ simulation ammonia nitrogen water was prepared with ammonium chloride. The concentration of water was 2, 4, 6, 8, 10, 15, 20, $25 \mathrm{mg} / \mathrm{L}$, respectively. One coal cinder-zeolite ball was added into each water sample and shocked constantly at $25{ }^{\circ} \mathrm{C}$ for $24 \mathrm{~h}$. The concentration of ammonia nitrogen adsorption equilibrium was determined and the adsorption of ammonia nitrogen was calculated.

5) Thermal regeneration performance of the sorbent

The $200 \mathrm{ml}$ simulation water was prepared with ammonium chloride $(10 \mathrm{mg} / \mathrm{L})$. The influence of the regeneration time and temperature for the regeneration efficiency were studied, under the conditions of $2,4,6 \mathrm{~h}$ at $170^{\circ} \mathrm{C}$, and $70,120,170{ }^{\circ} \mathrm{C}$ for $4 \mathrm{~h}$.

\section{Results and Discussion}

\section{Characterization of coal cinder-zeolite ball.}

The specific surface area of the coal cinder before and after pretreatment were $13.509 \mathrm{~m}^{2} / \mathrm{g}$, $22.141 \mathrm{~m}^{2} / \mathrm{g}$, respectively. Because in the process of pretreatment, metals may leach out, and hydrochloric acid may react with Sulfide, alumina, etc[Teng Zonghuan,2007]. Then the internal structure gets more loose, and the porosity increases. SEM of coal cinder-zeolite ball is shown in figure1. There are rich pores on the sorbent surface, and the uneven structure can provide larger 
surface area and more adsorption sites for the adsorption of ammonia nitrogen in water.

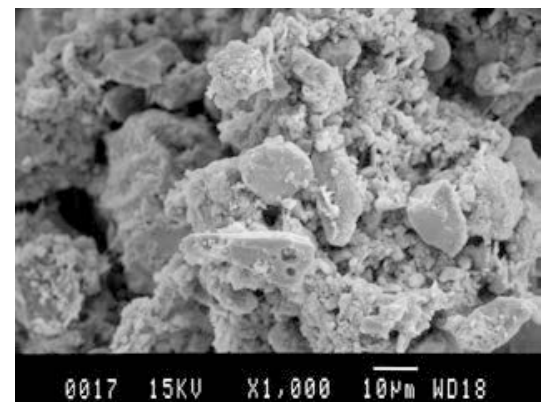

\section{Adsorption kinetics.}

Fig.1 SEM of coal cinder-zeolite ball

The process of adsorption kinetic was measured, and the results was showed in figure 2.The adsorption rate was relatively fast in the first $300 \mathrm{~min}$, and then slowed down gradually.

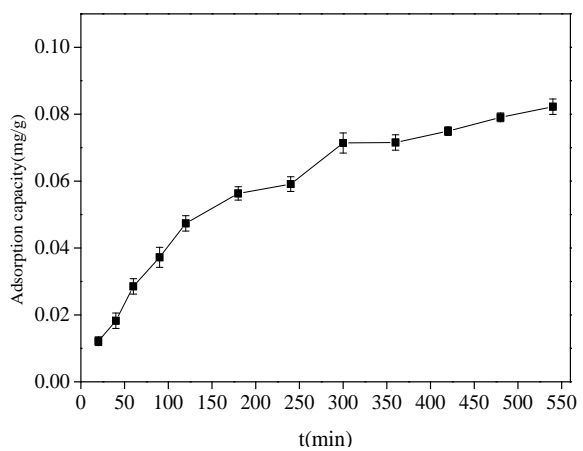

To better understand the mechanism of the adsorption process of ammonia nitrogen by coal cinder-zeolite ball, the experimental data were fitted with pseudo-first order kinetic model and pseudo-second order kinetic, respectively. The kinetic parameters obtained from the straight line fitting for ammonia nitrogen were showed in Table 1.

Table 1 Kinetic parameters obtained from the straight line fitting for ammonia nitrogen

\begin{tabular}{cccc}
\hline & $q_{e}(\mathrm{mg} / \mathrm{g})$ & $k_{1}\left(\mathrm{~min}^{-1}\right) / k_{2}(\mathrm{~g} /(\mathrm{mg} \cdot \mathrm{min})$ & $R^{2}$ \\
\hline $\begin{array}{c}\text { pseudo-first } \\
\text { order model }\end{array}$ & 0.0812 & 0.00663 & 0.988 \\
pseudo-second order model & 0.106 & 0.0558 & 0.992 \\
\hline
\end{tabular}

As seen from Table 1, the linear regression analysis of the second order rate equation gave a high $R^{2}$ value, which suggested that the sorption of ammonia nitrogen follows the pseudo-second order model. The same conclusion was also obtained from the study on the adsorption effect of ammonia nitrogen using fly ash [Uğurlu,2011].The pseudo-second order model is based on the assumption that the adsorption rate is controlled by the chemical adsorption mechanism[Ho,1999].So the adsorption process of ammonia nitrogen by the sorbent was affected by the chemical properties of sorbent and pollutants.

\section{Adsorption isotherm.}

Under the condition of $25^{\circ} \mathrm{C}$, isothermal liner equation of ammonia nitrogen removal by coal cinder-zeolite ball was shown in figure5. The experimental data were fitted with Langmuir equation and Freundlich equation, respectively. The parameters obtained from the straight line fitting were listed in the table 2 . 


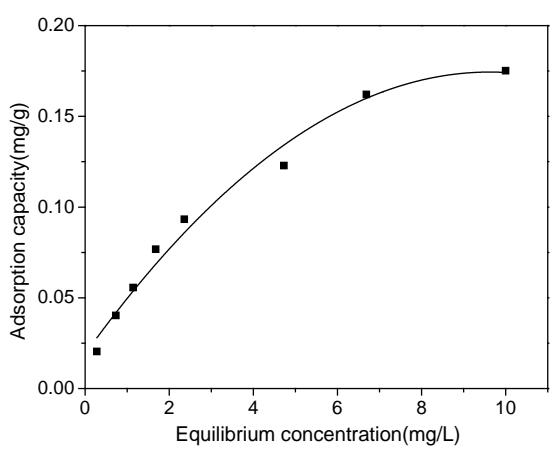

Fig.5 Isothermal liner equation of ammonia nitrogen removal by coal cinder-zeolite honeycombed sorbent

Table 2 Adsorption equation parameters obtained from the straight line fitting for ammonia nitrogen

\begin{tabular}{rccccc}
\hline \multicolumn{3}{c}{ Freundlich } & \multicolumn{3}{c}{ Langmuir } \\
\hline$K_{\mathrm{F}}(\mathrm{mg} / \mathrm{g})$ & $n$ & $R^{2}$ & $q_{\max }(\mathrm{mg} / \mathrm{g})$ & $b(\mathrm{~L} / \mathrm{mg})$ & $R^{2}$ \\
0.0494 & 1.642 & 0.981 & 0.1798 & 0.444 & 0.991 \\
\hline
\end{tabular}

As seen from the table2, Langmuir isotherm model fit more for the adsorption process $\left(R^{2} \geq 0.99\right)$ than Freundlich isotherm model $\left(R^{2} \geq 0.98\right)$. Therefore, ammonia nitrogen adsorption in the sorbent surface mainly is monolayer adsorption and heterogeneous adsorption reaction[Alshameri,2014] [Yin,2007]. And the adsorption capacity of ammonia nitrogen calculated from Langmuir equation was $0.18 \mathrm{mg} / \mathrm{g}$, which was larger than that obtained from coal cinder alone $(0.030 \mathrm{mg} / \mathrm{g})$ [ Zheng Yue,2011].

\section{Thermal regeneration performance of the sorbent.}

1) The influence of the regeneration time

Under the condition of $170^{\circ} \mathrm{C}$, regeneration time was design with 2,4,6h.As seen from figure8, the regeneration efficiency were $64 \%, 74 \%, 61 \%$, respectively. The best regeneration efficiency was obtained when the regeneration time was $4 \mathrm{~h}$.The regeneration efficiency was decline with the the regeneration time prolong. It is due to the high temperature environment in a long time will lead to the collapse of the pore structure, and decrease of specific surface area[Bai Yujie,2012].

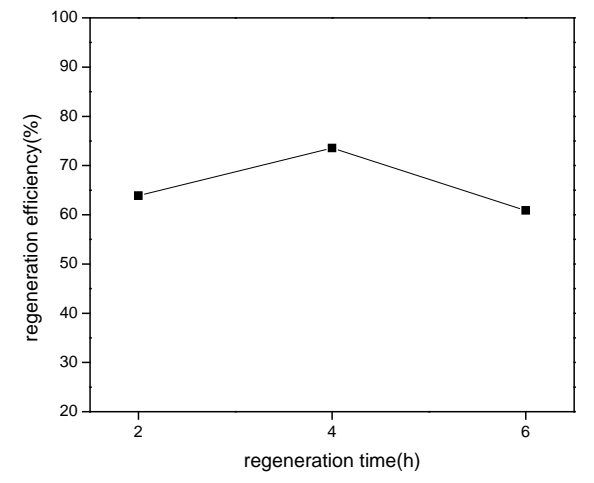

Fig.8 The influence of the regeneration time for the regeneration efficiency

2) The influence of the regeneration temperature

When the regeneration time was $4 \mathrm{~h}$, the regeneration temperature was designed with $70^{\circ} \mathrm{C}, 120^{\circ} \mathrm{C}, 170^{\circ} \mathrm{C}$.

The regeneration efficiency were 57\%,72\%,74\%, respectively. The regeneration efficiency increased with the regeneration temperature increasing. While the regeneration efficiency was hardly to promote as regeneration temperatures get higher. 


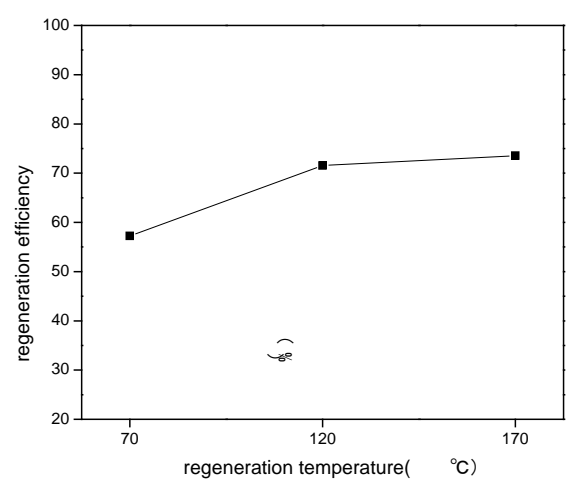

Fig.9 The influence of the regeneration temperature for the regeneration efficiency

\section{Conclusion}

The coal cinder-zeolite honeycombed sorbent has a large amount of pores on the surface and the uneven structure can provide larger surface area and more adsorption sites for the adsorption of ammonia nitrogen in water. The adsorption process fit well with pseudo-second order model and Langmuir isotherm model, which indicates a complicated chemical adsorption process. In addition ammonia nitrogen adsorption in the sorbent surface mainly is monolayer adsorption. And the adsorption capacity of ammonia nitrogen calculated from Langmuir equation was $0.18 \mathrm{mg} / \mathrm{g}$. And the sorbent has a good regeneration performance. The regeneration efficiency could achieve $74 \%$ under the regeneration condition of $170 \quad{ }^{\circ} \mathrm{C}, 4 \mathrm{~h}$.

\section{Acknowledgments}

This study was supported by the National Water Pollution Control and Management Technology Major Project of China (No. 2013ZX07202-007).

* Corresponding author at: Ocean University of China, College of Environmental Science and Engineering, 238\# Songling Road, Qingdao 266100, PR China.

Tel.: +8653266782356

\section{References}

[1] Alinnor I J. Adsorption of heavy metal ions from aqueous solution by fly ash[J]. Fuel, 2007, 86(5): 853-857

[2] Alshameri A, Yan C, Al-Ani Y, et al. An investigation into the adsorption removal of ammonium by salt activated Chinese (Hulaodu) natural zeolite: Kinetics, isotherms, and thermodynamics[J]. Journal of the Taiwan Institute of Chemical Engineers, 2014, 45(2): 554-564

[3] Bai Yujie, Zhang Aili, Zhou Jiti. Study on treatment of methylene blue wastewater by fly ash adsorption-fenton and thermal regeneration[J]. Environmental Science, 2012, 33(7):2419-3426

[4] Chen Lin, Wu Yahong, Yu Jian, et al. Modification of PVA adhesive by Succinic acid and its performance testing[J].Chemistry \& Bioengineering, 2012, 29(4): 15-17

[5] Chen Lirong Li Yumei Du Mingzhan. Adsorption of ammonia nitrogen in rare-earth wastewater by modified fly ash[J]. Chinese Journal of Environmental Engineering, 2013, 7(2): 518-522

[6] Gao Junmin, Zhen Zegen, Wang Yan, et al. Application of zeolite in water treatment[J]. Journal of Chongqing Jianzhu University. 2001, 23(1): 114-117

[7] Ho Y S, McKay G. Pseudo-second order model for sorption processes[J]. Process Biochemistry, 1999, 34 (5):451-465.

[8] Kuang Deshun, Li Jun, Zhang Wei, et al. Documentary report of nitrogen pollution in Liaohe estuary area[J]. Environmental Protection, 2010 (22):60-62 
[9] Liu Q, Guo H, Shan Y. Adsorption of fluoride on synthetic siderite from aqueous solution[J]. Journal of Fluorine Chemistry, 2010, 131(5): 635-641

[10] Liu Yong, Liu Ya, Ren Yuelin, et al. Synthesis and defluoridation performance of humic acid sodium base absorbent modified by metal ion, China Environmental Science, 2014, 34(4):942-950

[11] Sprynskyy M, Lebedynets M, Terzyk A P, et al. Ammonium sorption from aqueous solutions by the natural zeolite transcarpathian clinoptilolite studied under dynamic conditions[J]. Journal of Colloid and Interface Science, 2005, 284(2): 408-415

[12] Tang Dengyong, Zheng Zheng, Guo Zhaobing, et al. Study on ammonia nitrogen adsorption from low concentration wastewater by modified zeolite and its desorption[J]. Chinese Journal of Environmental Engineering, 2011, 5(2): 293-296

[13] Teng Zonghuan, Chen Jianzhong. The adsorption mechanism of modified fly ash and its application in wastewater treatment [J]. Southwest water \& wastewater, 2007, 29(4): 23-27

[14] Uğurlu M, Karaoğlu M H. Adsorption of ammonium from an aqueous solution by fly ash and sepiolite: isotherm, kinetic and thermodynamic analysis[J]. Microporous and Mesoporous Materials, 2011, 139(1): 173-178

[15] Wang S, Wu H. Environmental-benign utilisation of fly ash as low-cost adsorbents[J]. Journal of Hazardous Materials, 2006, 136(3): 482-501

[16] Yin C Y, Aroua M K, Daud W M A W. Review of modifications of activated carbon for enhancing contaminant uptakes from aqueous solutions[J]. Separation and Purification Technology, 2007, 52(3): 403-415.

[17] Zheng Yue, Liu Fang, Wu Yonggui. Ammonia nitrogen adsorption on coal fly Ash[J]. Environmental Science \& Technology, 2011, (1): 4-7 